\title{
DESEMPENHO ANALÍTICO DE LABORATÓRIOS PRESTADORES DE SERVIÇO NA DETERMINAÇÃO DE METAIS EM ÁGUAS
}

\author{
Wilson F. Jardim* e Fernando F. Sodré \\ Departamento de Química Analítica, Instituto de Química, Universidade Estadual de Campinas, CP 6154, 13084-862 \\ Campinas - SP, Brasil
}

Recebido em 9/4/08; aceito em 12/9/08; publicado na web em 26/1/09

\begin{abstract}
ANALYTICAL PERFORMANCE OF CONTRACTOR LABORATORIES IN THE DETERMINATION OF METALS IN WATER. Analytical laboratories are expected to produce reliable results. Decision makers are guided in their actions (financial, legal and environmental) using analytical data provided by numerous laboratories. This work aimed to evaluate the analytical performance of Brazilian laboratories on producing trustworthy results. Nineteen laboratories, accredited and non-accredited ones, were contracted to analyze a USGS (United States Geological Survey) certified water sample for 17 chemical elements (mostly metals) without knowing the origin of the sample. Considering all the results produced, only $35 \%$ of them were valid. Three laboratories present satisfactory performances, whereas the majority showed a very poor overall performance. The outcomes of this work show the need for a more effective analytical quality program to Brazilian laboratories.
\end{abstract}

Keywords: laboratory performance; metals; quality program.

\section{FIDEDIGNIDADE DE RESULTADOS ANALÍTICOS E GESTÃO DA QUALIDADE}

Laboratórios que prestam serviço em análises químicas têm como compromisso maior a fidedignidade do resultado gerado, uma vez que este é, geralmente, o grande balizador em tomadas de decisão, o que quase sempre se traduz em recursos financeiros e em ações legais, em especial nas questões ambientais. Ao gerar um resultado fidedigno, ou seja, aquele que apresenta exatidão e precisão aceitáveis dentro de condições pré-estabelecidas, é necessário que um laboratório coloque em prática seu programa de gestão da qualidade. Neste caso, um resultado analítico pode ser considerado aceito se for obtido por meio de referências pré-estabelecidas e métodos validados, através de uma cadeia contínua de comparações, todas tendo incertezas estabelecidas. ${ }^{1}$ Entretanto, a utilização de métodos validados, sejam eles oficiais ou padrão, não garante que o resultado fornecido seja fidedigno.

A validação de um método é, normalmente, realizada avaliando-se inúmeros parâmetros de mérito, tais como repetitividade, reprodutibilidade, número de medidas, seletividade, recuperação, linearidade, limites de detecção (LD) e quantificação (LQ), entre outros. ${ }^{2,3}$ Assim, é importante que laboratórios sempre validem seus métodos rotineiros como forma de estabelecer as especificidades de cada ensaio e, ao mesmo tempo, permitir ao analista e ao contratante conhecer a confiabilidade do resultado gerado.

Tendo em vista a importância em se gerar resultados confiáveis que subsidiem ações futuras do contratante, sistemas de gestão da qualidade também se estendem aos laboratórios que prestam serviço em análises químicas. Neste caso, o Controle de Qualidade e a Garantia da Qualidade (QA/QC - quality assurance/quality control) devem ser praticados rotineiramente. ${ }^{3}$

No Brasil, laboratórios prestadores de serviço têm sentido uma pressão cada vez maior para que se engajem em programas de qualidade, exigência esta que surge também por parte do contratante. O Instituto Nacional de Metrologia, Normalização e Qualidade In-

*e-mail: wfjardim@iqm.unicamp.br dustrial (INMETRO), por exemplo, tem provido condições para que os laboratórios obtenham sua acreditação segundo as instruções da NBR ISO/IEC 17025, que estabelece requisitos gerenciais e técnicos para a implantação do sistema de gestão da qualidade em laboratórios de ensaio e calibração. ${ }^{4}$ Outros sistemas de gestão, tais como o Programa para as Boas Práticas de Laboratório (BPL) ${ }^{5}$ estabelecido pelo Instituto Brasileiro do Meio Ambiente e dos Recursos Naturais Renováveis (IBAMA) em conjunto com o INMETRO e a série ISO 9000, preconizada pela International Organization for Standardization, também fornecem uma abordagem sistêmica para a gestão da qualidade dos serviços prestados.

Um laboratório pode apresentar todos os requisitos técnicos que demonstrem o atendimento às exigências de diferentes sistemas de gestão, porém, mesmo assim, gerar um resultado inexato. Nestes casos, a maneira mais prática, corriqueira e segura de se verificar a exatidão dos resultados de medição, conferir rastreabilidade ao resultado e/ou validar o método de ensaio em ambiente intralaboratorial é utilizar materiais de referência certificados (MRC). ${ }^{3,6}$

Os MRC possuem um ou mais valores de propriedades acompanhados por uma incerteza para um nível de confiança pré-estabelecido. Embora possam ser produzidos por meio da utilização de métodos primários, estes materiais são, geralmente, obtidos a partir de resultados gerados por um consórcio de laboratórios. ${ }^{6}$ Os valores obtidos para a determinação de elementos/compostos/parâmetros químicos são certificados por procedimentos que conferem rastreabilidade aos resultados da medição configurando o valor denominado certificado, ou seja, aquele que se aproxima ao máximo do verdadeiro. Convém mencionar que o valor verdadeiro não existe na realidade, mas é previamente estabelecido como o mais aceitável.

Laboratórios acreditados e mesmo aqueles não acreditados, mas que possuem preocupação com a qualidade dos resultados fornecidos ao contratante, participam de programas nacionais e/ou internacionais em que MRC são analisados periodicamente. Estes exercícios de intercalibração, ou ensaios de proficiência, prestam-se à obtenção do reconhecimento formal da competência técnica do laboratório e, igualmente, constituem elementos essenciais à fidedignidade dos resultados. 
Em virtude da necessidade de se conhecer a qualidade dos serviços prestados por laboratórios de análises químicas no Brasil, sob o ponto de vista do resultado fornecido ao contratante, este estudo buscou avaliar o desempenho de alguns laboratórios na análise de uma amostra de água certificada quanto ao conteúdo de 17 elementos, a maioria deles metais. O desempenho dos laboratórios, ou seja, a capacidade em fornecer resultados fidedignos, foi avaliado tomando-se por base unicamente a exatidão dos resultados gerados. No entanto, outros aspectos também foram analisados, tais como a forma de apresentação dos resultados e o conteúdo dos ditos laudos, boletins ou relatórios de análise.

\section{ESCOLHA DOS LABORATÓRIOS, DA AMOSTRA E DOS ANALITOS}

Dezenove laboratórios que analisam amostras de água, distribuídos em todo o território nacional, foram avaliados neste estudo, sendo que a maioria $(37 \%)$ se encontra situada na região Sudeste. A fim de preservar a identidade de cada um dos laboratórios, os mesmos foram identificados a partir de um número, o qual é único para cada laboratório.

Para a avaliação dos laboratórios quanto à exatidão dos resultados obtidos, foi escolhida uma amostra de água, junto a United States Geological Survey (USGS), cujos valores certificados para alguns elementos químicos apresentavam, na maioria dos casos, a mesma ordem de grandeza daqueles preconizados pela Portaria MS-518 do Ministério da Saúde, ${ }^{7}$ que versa sobre critérios de potabilidade da água. É importante mencionar que todos os laboratórios foram informados quanto à necessidade de analisar a amostra à luz dos critérios de potabilidade. Dentre os 28 elementos químicos certificados pela USGS na amostra escolhida, apenas 17 foram escolhidos para a realização deste estudo. A Tabela 1 traz os valores certificados e valores máximos permitidos pela Portaria 518 para os elementos

Tabela 1. Valores legislados pela Portaria 518 do Ministério da Saúde comparados aos valores da amostra certificada para alguns elementos químicos. Valores em $\mathrm{mg} \mathrm{L}^{-1}$

\begin{tabular}{|c|c|c|c|c|c|}
\hline \multirow{2}{*}{$\frac{\text { Elemento }}{\text { Alumínio }}$} & \multirow{2}{*}{$\frac{\text { Símbolo }}{\mathrm{Al}}$} & \multicolumn{3}{|c|}{ Valor Certificado } & \multirow{2}{*}{$\frac{\text { Portaria } 518}{0,2}$} \\
\hline & & 0,132 & \pm & 0,020 & \\
\hline Antimônio* & $\mathrm{Sb}$ & 0,0562 & \pm & 0,0067 & 0,005 \\
\hline Arsênio* & As & 0,0566 & \pm & 0,0054 & 0,010 \\
\hline Bário & $\mathrm{Ba}$ & 0,507 & \pm & 0,022 & 0,7 \\
\hline Boro* & B & 0,141 & \pm & 0,012 & NL \\
\hline Cádmio & $\mathrm{Cd}$ & 0,0061 & \pm & 0,0005 & 0,005 \\
\hline Chumbo & $\mathrm{Pb}$ & 0,0181 & \pm & 0,0027 & 0,010 \\
\hline Cobre & $\mathrm{Cu}$ & 0,0202 & \pm & 0,0020 & 2 \\
\hline Cromo & $\mathrm{Cr}$ & 0,0186 & \pm & 0,0021 & 0,05 \\
\hline Ferro & $\mathrm{Fe}$ & 0,0907 & \pm & 0,0089 & 0,3 \\
\hline Manganês & $\mathrm{Mn}$ & 0,0378 & \pm & 0,0030 & 0,1 \\
\hline Molibdênio & Mo & 0,112 & \pm & 0,010 & NL \\
\hline Níquel & $\mathrm{Ni}$ & 0,0563 & \pm & 0,0047 & NL \\
\hline Selênio** & $\mathrm{Se}$ & 0,0112 & \pm & 0,0020 & 0,010 \\
\hline Sódio & $\mathrm{Na}$ & 21,4 & \pm & 0,8 & 200 \\
\hline Vanádio & $\mathrm{V}$ & 0,0342 & \pm & 0,0032 & NL \\
\hline Zinco & $\mathrm{Zn}$ & 0,072 & \pm & 0,0044 & 5 \\
\hline
\end{tabular}

* semimetais; ** não-metal; NL: não legislado. químicos selecionados.

As amostras certificadas encontravam-se originalmente acondicionadas em frascos de polietileno de alta densidade com capacidade de $250 \mathrm{~mL}$. Além disso, estavam preservadas em ácido nítrico conforme recomendado pelo Standard Methods for the Examination of Water and Wastewater (SMEWW). ${ }^{8}$ Os frascos foram enviados para os laboratórios prestadores de serviço em caixas térmicas contendo gel selado para garantir a refrigeração da amostra durante o transporte. As amostras foram despachadas de modo a chegarem aos laboratórios no prazo máximo de $48 \mathrm{~h}$. Deste modo, qualquer desvio observado no resultado gerado não poderia ser atribuído ao transporte/preservação da amostra.

\section{DESEMPENHO DOS LABORATÓRIOS}

A Figura 1 mostra gráficos em que as concentrações obtidas, para todos os elementos investigados, são lançadas em função das concentrações certificadas. São mostrados apenas os resultados obtidos pelos laboratórios (LAB) 5, 11 e 12, porém todos os laboratórios foram submetidos a este tipo de avaliação. Os demais gráficos estão disponibilizados como Material Suplementar. Valores obtidos experimentalmente são mostrados como círculos preenchidos, enquanto que valores de LD ou LQ são mostrados como círculos vazios. Uma reta representa a situação em que todos os dados obtidos são idênticos aos valores certificados. Assim, quanto mais próximos da reta guia estiverem os círculos, mais próximos aos valores certificados serão os resultados apresentados pelo laboratório. Ainda, considerando-se que os gráficos são mostrados em escala logarítmica, é importante observar que cada marca principal corresponde a uma década de grandeza.

Os três laboratórios avaliados na Figura 1 apresentaram resultados distintos quanto ao desempenho analítico. Nota-se, por exemplo, que os LAB 12 e 5 apresentaram grande parte dos valores próximos à reta utilizada como guia de exatidão.

No gráfico referente aos resultados do LAB 12, o elemento boro (B), reportado em função do valor de LQ/LD, situou-se acima da reta guia. Neste caso, é importante mencionar que círculos vazios situados na região acima da reta indicam que o método analítico empregado pelo laboratório não foi capaz de gerar valores tão baixos quanto a concentração certificada. Este resultado não prejudica a fidedignidade do resultado, embora demonstre que o método não foi apropriado para determinação de concentrações baixas de boro.

O oposto do comportamento observado para o boro (LAB 12) foi verificado para elemento selênio (Se), reportado pelo LAB 5 em termos do valor de LQ/LD. A localização do resultado situando-se abaixo da reta guia evidencia que o laboratório não foi capaz de quantificar um valor que estava mais de 10 vezes acima do limite de detecção, o que não é um bom desempenho. Assim como no caso do Se, o LAB 12 também não detectou os elementos cromo $(\mathrm{Cr})$ e alumínio (Al), cujos valores certificados são maiores que o limite reportado.

Em um outro extremo está o LAB 11, que apresentou um desempenho sofrível quanto à exatidão dos resultados apresentados. Neste caso, as concentrações obtidas para 15 dos 17 elementos investigados, quando lançadas no gráfico, situaram-se muito distante da reta guia. Os elementos $\mathrm{Cr}$ e $\mathrm{Al}$, ambos reportados em termos de LQ/LD, apresentaram resultados mais próximos da reta guia. O elemento bário (Ba) também apresentou um resultado satisfatório, uma vez que foi apresentado em função do valor de LQ/LD e se situou acima da reta guia. O LAB 11 quantificou apenas 5 elementos (círculos preenchidos), sendo que todos apresentaram valores inexatos. Neste conjunto de dados, os resultados mais discrepantes são referentes aos elementos cobre $(\mathrm{Cu})$ e zinco $(\mathrm{Zn})$ que foram reportados em 

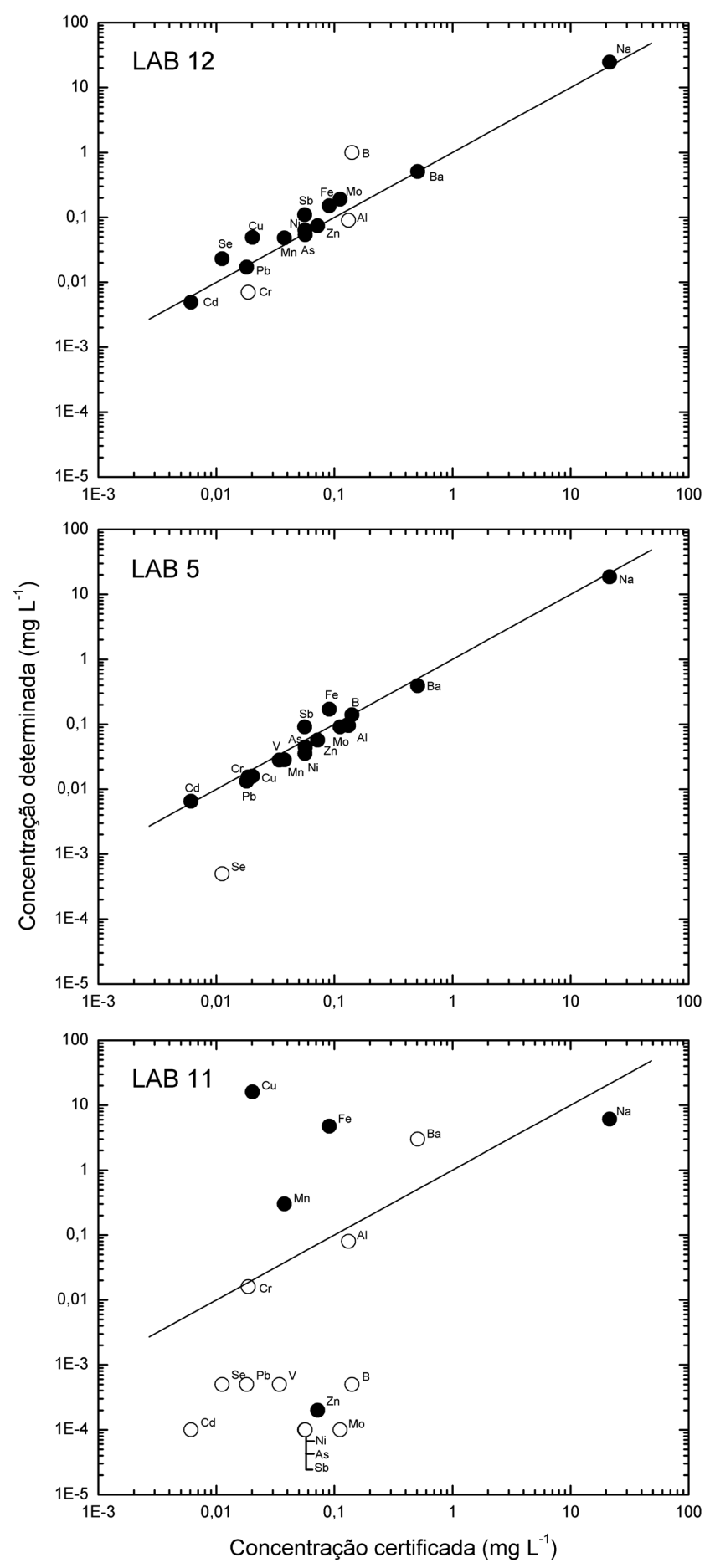

Figura 1. Distribuição dos resultados obtidos pelos laboratórios 12, 5 e 11 em função dos valores certificados. A reta indica valores obtidos e certificados idênticos. Círculos cheios são resultados experimentais e círculos não preenchidos são valores de limite de detecção ou de quantificação

concentrações centenas de vezes distantes do valor certificado. Resultados igualmente discrepantes são os mostrados para 9 elementos reportados em termos de $\mathrm{LQ} / \mathrm{LD}$ e situados abaixo da reta guia. $\mathrm{O}$ caso mais absurdo é o do elemento molibdênio (Mo), cujo valor de $\mathrm{LQ} / \mathrm{LD}$ apresentado foi de $0,0001 \mathrm{mg} \mathrm{L}^{-1}$, enquanto que o valor certificado é de $0,112 \pm 0,011 \mathrm{mg} \mathrm{L}^{-1}$. Ou seja, o LAB 11 não foi capaz de quantificar Mo em concentrações cerca de 1100 vezes acima do limite informado.

Os demais laboratórios apresentaram-se entre os extremos repre- sentados pelos LAB 5 e 11, com exceção do LAB 16 que reportou concentrações iguais a $0,0 \mathrm{mg} \mathrm{L}^{-1}$ (!) para 6 dos 14 elementos que investigou. Avaliando-se o desempenho global, com relação à exatidão dos resultados apresentados, observou-se que $37 \%$ dos laboratórios apresentaram desempenhos tidos como sofríveis, com elevada dispersão dos resultados em torno do valor considerado verdadeiro e apenas 3 laboratórios (16\%) desempenharam um papel adequado, em que foi observada maior proximidade dos resultados em torno da reta guia de exatidão. Os demais laboratórios (47\%) permaneceram em uma situação intermediária, onde pequenos acertos na gestão da qualidade poderiam levá-los a uma melhoria quanto à exatidão dos resultados gerados.

Neste estudo, o sódio ( $\mathrm{Na}$ ) foi considerado o elemento balizador do desempenho dos laboratórios, tendo-se em vista que sua concentração na amostra certificada é relativamente elevada. Nestes níveis de concentração sua determinação analítica é facilitada ao se empregar métodos de emissão atômica com chama, os quais são, até certo ponto, isentos de interferência e demandam um equipamento de baixo custo. Além disso, ao se comparar a incerteza padrão dos valores certificados (Tabela 1), nota-se que o Na apresenta o menor desvio relativo $(3,7 \%)$, enquanto que os demais elementos apresentam desvios na faixa de 4,3 a $18 \%$. Este aspecto evidencia a facilidade em se obter um resultado analítico fidedigno com relação aos níveis de Na na amostra certificada.

Todos os laboratórios apresentaram resultados quantitativos para o elemento Na. Entretanto, nem todos apresentaram resultados com níveis de exatidão aceitáveis. O LAB 11, por exemplo, apresentou um resultado insatisfatório, uma vez que foi quantificada uma concentração de Na cerca de três vezes menor que a certificada (Figura 1). Neste trabalho, a faixa de aceitação, em termos da exatidão do resultado, foi estipulada com base nos critérios estabelecidos em ensaios de proficiência interlaboratoriais. ${ }^{9,10}$

Em um ensaio de proficiência, a interpretação dos resultados obtidos pelos laboratórios é balizada considerando-se a faixa de aceitação do resultado gerado, a qual é calculada a partir da incerteza, usualmente o desvio padrão, associada ao valor certificado. Por exemplo, na amostra analisada o valor certificado $(\mu)$ do Na é de 21,4 $\mathrm{mg} \mathrm{L}^{-1}$ com a incerteza padrão $(\sigma)$ de $0,8 \mathrm{mg} \mathrm{L}^{-1}$. Sob o ponto de vista estatístico, 99\% $(\mathrm{P}<0,01)$ dos resultados obtidos para esta amostra encontram-se em um intervalo em torno de 21,4 com amplitude igual a três vezes a incerteza padrão, ou seja, $\mu \pm 3 \sigma$. Assim, se aceita como válido qualquer resultado que esteja no intervalo $21,4 \pm 3$ x $0,8 \mathrm{mg}$ $\mathrm{L}^{-1}$. Isto representa uma variação de $2,4 \mathrm{mg} \mathrm{L}^{-1}$ em torno do valor certificado de $21,4 \mathrm{mg} \mathrm{L}^{-1}$. Portanto, se um laboratório forneceu um valor para a concentração de $\mathrm{Na}$ entre 19,0 e $23,8 \mathrm{mg} \mathrm{L}^{-1}$, seu resultado será considerado aceito. Obviamente, quanto mais próximo de 21,4 for o resultado, melhor o desempenho do laboratório.

Seguindo este critério, a Figura 2 mostra o desempenho de todos os laboratórios frente à determinação dos metais $\mathrm{Na}, \mathrm{Cr}$ e ferro (Fe total). Para os demais elementos deve-se consultar o material suplementar.

Os gráficos mostrados na Figura 2 foram construídos a partir da ordenação crescente de todos os resultados obtidos. São mostrados no gráfico, na forma de círculos preenchidos e vazios, apenas aqueles resultados situados dentro da faixa de aceitação, ou seja, três vezes a incerteza padrão em torno do valor certificado. Este tipo de gráfico permite avaliar a capacidade de todos os laboratórios em obter uma resposta analítica fidedigna com relação a um dado elemento.

Nota-se que para o $\mathrm{Na}$, apenas 9 dos 19 laboratórios, ou seja, $47 \%$, conseguiram quantificar o metal dentro da faixa estatisticamente aceitável. Este resultado é preocupante considerando-se o caráter balizador do elemento investigado. Pode-se observar também que 2 laboratórios superestimaram a concentração de $\mathrm{Na}$, enquanto que 8 

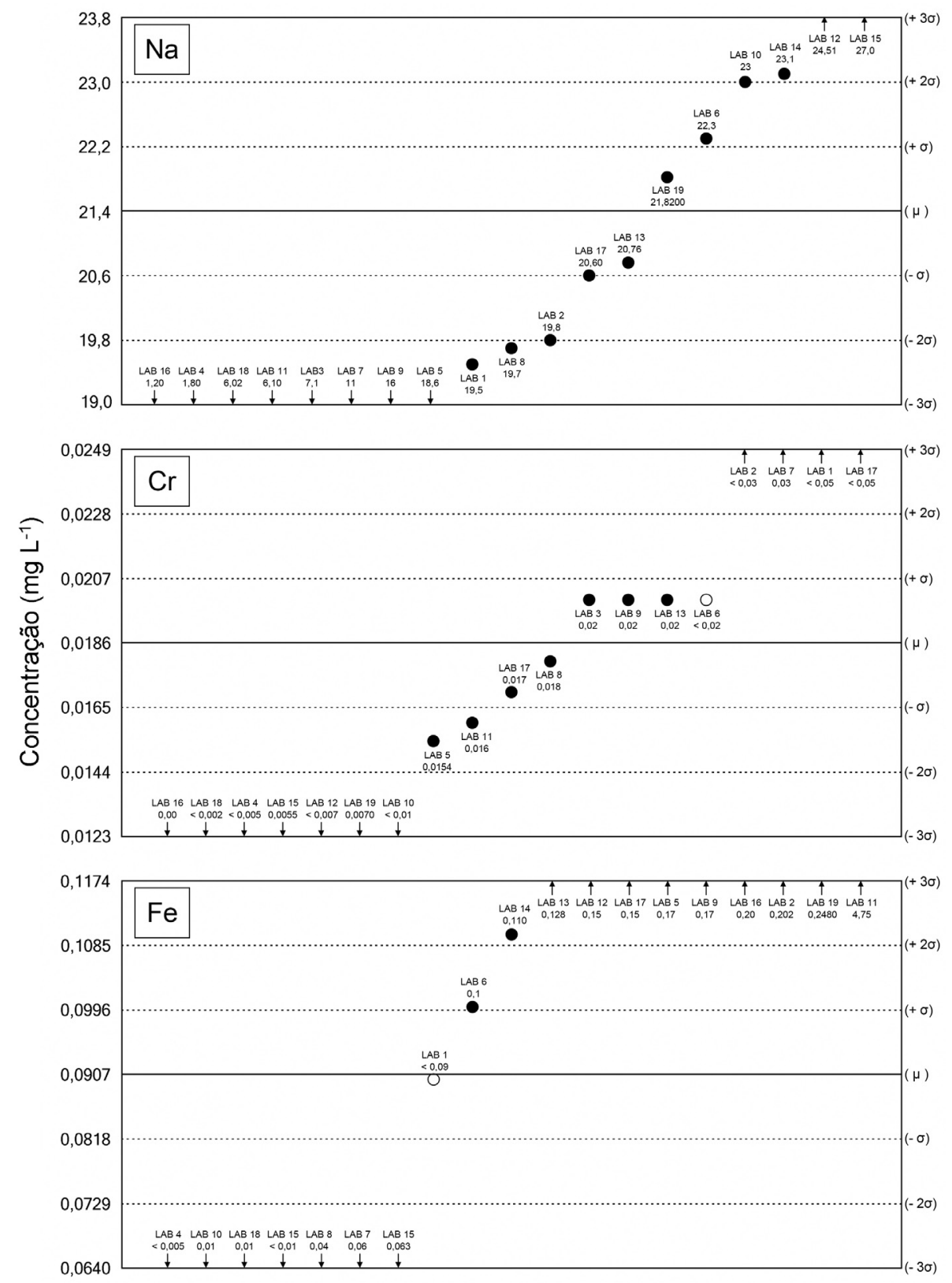

Figura 2. Variabilidade das concentrações de sódio, cromo e ferro, em ordem crescente, dentro da faixa de aceitação ( $\mu \pm 3 \sigma)$. Círculos cheios são resultados experimentais e círculos não preenchidos são valores de limite de detecção ou de quantificação

(42\%) apresentaram concentrações abaixo da faixa de aceitação. Os piores resultados ficaram por conta dos $\mathrm{LAB} 16$ e 4 , que reportaram valores de 1,20 e 1,80 $\mathrm{mg} \mathrm{L}^{-1}$ de $\mathrm{Na}$, respectivamente, na amostra que continha $21,4 \mathrm{mg} \mathrm{L}^{-1}$, um erro relativo superior a $90 \%$.

Com relação ao $\mathrm{Cr}$, 8 resultados encontraram-se situados dentro da faixa de aceitação, sendo que apenas um foi reportado com base no valor de LQ/LD. Apesar da menor quantidade de resultados dentro da faixa de aceitação, em comparação ao $\mathrm{Na}$, observa-se uma maior quantidade de resultados válidos para o $\mathrm{Cr}$ com 3 laboratórios reportando valores de LQ ou LD superiores ao certificado. Neste caso, mesmo fora da faixa de aceitação, os LAB 1, 2 e 17 apresentaram valores coerentes que não afetam a fidedignidade do resultado, mas apontam para a dificuldade dos laboratórios em determinar concentrações baixas de $\mathrm{Cr}$.

O Fe foi o elemento mais problemático dentre os 17 investigados. Três resultados, sendo 2 quantificados (LAB 14 e 16) e um reportado como LQ/LD (LAB 1), permaneceram dentro da faixa estatisticamen- te aceitável. Nenhum outro resultado acima da faixa de aceitação foi reportado com base nos valores de LQ ou LD. Conseqüentemente, o Fe apresentou a menor porcentagem de resultados válidos (16\%) considerando-se todos os elementos investigados pelos laboratórios. A porcentagem de resultados válidos para todos os elementos avaliados encontra-se na Tabela 2.

Pode-se observar, na Tabela 2, que as maiores porcentagens de resultados válidos gerados pelos laboratórios foram obtidas para o $\mathrm{Cr}$ (58\%), seguido do vanádio (V) (53\%), do Se (50\%) e do Na (47\%). A maior surpresa foi o desempenho obtido para Se, para o qual 9 resultados se situaram dentro da faixa de aceitação, embora apenas 4 tenham sido, de fato, quantificados e 5 reportados com base nos valores de LD ou LQ. Os piores resultados foram obtidos para o Fe, conforme mostrado na Figura 2, seguido do antimônio $(\mathrm{Sb})(22 \%)$ e dos elementos cobre $(\mathrm{Cu})$, molibdênio (Mo), níquel (Ni) e zinco (Zn), todos com $26 \%$ de resultados válidos. Em média, dentre os 315 resultados gerados neste exercício, apenas $35 \%$ foram considerados válidos. 
Tabela 2. Número total de resultados, resultados válidos, valores médios determinados e erro relativo entre o valor certificado e o valor médio determinado para cada um dos elementos investigados

\begin{tabular}{|c|c|c|c|c|c|c|c|}
\hline \multirow{2}{*}{$\begin{array}{l}\text { Elemento } \\
\mathrm{Al}\end{array}$} & \multirow{2}{*}{$\begin{array}{c}\begin{array}{l}\text { Número de } \\
\text { Resultados }\end{array} \\
19\end{array}$} & \multirow{2}{*}{$\begin{array}{c}\begin{array}{c}\text { Resultados } \\
\text { válidos* } \\
(\%)\end{array} \\
32\end{array}$} & \multicolumn{3}{|c|}{$\begin{array}{l}\text { Valor Determinado } \\
\qquad\left(\mathrm{mg} \mathrm{L}^{-1}\right)^{\dagger}\end{array}$} & \multirow{2}{*}{$\begin{array}{l}\mathrm{N} \\
15\end{array}$} & \multirow{2}{*}{$\begin{array}{r}E_{r}^{\ddagger}(\%) \\
27,3\end{array}$} \\
\hline & & & 0,168 & \pm & 0,068 & & \\
\hline $\mathrm{Sb}$ & 18 & 22 & 0,056 & \pm & 0,023 & 12 & $-0,4$ \\
\hline As & 19 & 32 & 0,041 & \pm & 0,019 & 10 & $-27,6$ \\
\hline $\mathrm{Ba}$ & 19 & 32 & 0,439 & \pm & 0,134 & 15 & $-13,4$ \\
\hline B & 16 & 32 & 0,180 & \pm & 0,079 & 6 & 27,7 \\
\hline $\mathrm{Cd}$ & 19 & 37 & 0,005 & \pm & 0,002 & 11 & -18 \\
\hline $\mathrm{Pb}$ & 18 & 39 & 0,014 & \pm & 0,007 & 9 & $-22,7$ \\
\hline $\mathrm{Cu}$ & 19 & 26 & 0,025 & \pm & 0,011 & 12 & 23,8 \\
\hline $\mathrm{Cr}$ & 19 & 58 & 0,015 & \pm & 0,006 & 11 & $-19,4$ \\
\hline $\mathrm{Fe}$ & 19 & 16 & 0,121 & \pm & 0,040 & 15 & 33,4 \\
\hline $\mathrm{Mn}$ & 19 & 37 & 0,040 & \pm & 0,012 & 14 & 5,8 \\
\hline Mo & 19 & 26 & 0,116 & \pm & 0,064 & 11 & 3,6 \\
\hline $\mathrm{Ni}$ & 19 & 26 & 0,039 & \pm & 0,017 & 12 & $-30,7$ \\
\hline $\mathrm{Se}$ & 18 & 50 & 0,012 & \pm & 0,007 & 6 & 7,1 \\
\hline $\mathrm{Na}$ & 19 & 47 & 16,3 & \pm & 3,9 & 19 & $-23,8$ \\
\hline V & 17 & 53 & 0,030 & \pm & 0,004 & 8 & $-12,3$ \\
\hline $\mathrm{Zn}$ & 19 & 26 & 0,070 & \pm & 0,023 & 16 & $-2,8$ \\
\hline
\end{tabular}

*Valores dentro da faixa de aceitação $(\mu \pm 3 \sigma)$ somados aos reportados como LQ/LD acima da faixa de aceitação. Valor médio determinado com base nos valores contidos nos laudos após testes de rejeição de Cochran e Grubbs a 95\% de confiança. Incerteza obtida a partir do produto entre a estimativa do desvio padrão e o fator $t$ de student (95\%) dividido pela raiz quadrada de $\mathrm{N}$ (número de valores individuais). ${ }^{*}$ Erro relativo $\left[\mathrm{Er}=\left(x_{\mathrm{L}}-x_{\mathrm{C}}\right) / x_{\mathrm{C}} .100 \%\right]$ obtido a partir dos valores médios determinado $\left(x_{\mathrm{L}}\right)$ e certificado $\left(x_{\mathrm{C}}\right)^{2}$

Na Tabela 2 também são apresentados os valores médios, obtidos com base nos resultados fornecidos em todos os laudos de análise, para cada um dos 17 elementos investigados. Para obtenção destes valores, foram considerados apenas os resultados experimentais expressos numericamente. Valores reportados como LQ ou LD, foram excluídos deste exercício analítico. Todos os resultados, para cada elemento, foram submetidos aos testes de rejeição de Cochran e Grubbs..$^{10}$ Em ambos os casos, foi utilizada uma confiabilidade de $95 \%$. Após a rejeição de alguns resultados, foram calculados os valores médios, para cada elemento, e a estimativa do desvio padrão para cada conjunto de dados contendo $N$ valores individuais. Finalmente, foi obtida a variabilidade de cada conjunto de dados por meio de valores $t$ de Student a 95\% ( $\mathrm{P}<0,05)$.

Os resultados mostrados na Tabela 2 também trazem o erro relativo entre o valor determinado e o valor certificado para cada elemento. Nota-se que para 8 dos 17 dos elementos, o erro relativo foi superior a $20 \%$. Os maiores erros foram observados para o $\mathrm{Fe}(33,4 \%)$ e para o Ni $(-30,7 \%)$. O Na, considerado o elemento balizador, apresentou um erro relativo de $-23,8 \%$, uma vez que o valor médio determinado foi de $16,3 \mathrm{mg} \mathrm{L}^{-1}$ em oposição aos $21,4 \mathrm{mg} \mathrm{L}^{-1}$ da amostra certificada. No outro extremo, os menores erros relativos foram obtidos para o $\mathrm{Sb}$ $(-0,4 \%)$, seguido do $\mathrm{Zn}(-2,8 \%)$ e do Mo (3,6\%). Coincidentemente, estes três elementos também apresentaram a menor porcentagem de resultados válidos: $\mathrm{Sb}(22 \%), \mathrm{Zn}(26 \%)$ e Mo (26\%). Estes resultados devem ser considerados sem valor estatístico, uma vez que os critérios usados para a definição dos valores válidos, ou seja, a somatória entre resultados dentro da faixa de aceitação e resultados expressos como LD/LQ acima desta faixa, são diferentes daqueles empregados para a obtenção do valor de concentração médio para cada elemento.

Por outro lado, mesmo apresentando erros relativos baixos, os valores médios obtidos para os elementos $\mathrm{Sb}$, Zn e Mo são acompanhados de incerteza elevada. Dentre estes três elementos, o pior resultado foi obtido para o Mo que apresentou um valor médio de $0,116 \mathrm{mg} \mathrm{L}^{-1}$ com incerteza de $\pm 0,064 \mathrm{mg} \mathrm{L}^{-1}$, ou seja, uma imprecisão de $55 \%$. Considerando-se a incerteza padrão sobre o valor médio para todos os elementos investigados, verifica-se que 11 dos 17 resultados gerados apresentaram incertezas superiores a $40 \%$.

\section{DOCUMENTAÇÃO E ATENDIMENTO AO CONTRATANTE}

O desempenho, no mínimo razoável, dos laboratórios com relação à fidedignidade dos resultados analíticos pode ser estendido à forma de apresentação dos resultados por parte de cada laboratório. Recomenda-se que a apresentação dos resultados, em laudos, relatórios ou boletins de análise, seja realizada de forma clara, objetiva e, sobretudo, correta. Os documentos devem conter todas as informações necessárias para que o contratante possa compreender o conteúdo integral do documento e, igualmente, rastrear a qualidade dos resultados apresentados.

Com base nos laudos de análise verificou-se que cerca de dois terços dos resultados foram referenciados quanto ao método analítico empregado. Dentre estes resultados, a grande maioria (84\%) foi obtida a partir de métodos descritos no SMEWW. A espectroscopia de absorção atômica foi a ferramenta analítica mais utilizada, seguida da emissão atômica (plasma e chama) e da absorção molecular no UV-visível.

Apenas 12 laboratórios apresentaram, total ou parcialmente, valores referentes aos limites de quantificação/detecção dos métodos empregados. Sob o ponto de vista analítico, recomenda-se que concentrações inferiores ao limite do método sejam referenciadas em função do valor de LQ. Somente 5 laboratórios atenderam a esta recomendação, sendo que a maioria apresentou valores de LD. Além disso, nenhum laboratório especificou, em seus documentos, o procedimento empregado para a obtenção dos limites. Dois laboratórios apresentaram informações referentes a testes de recuperação, enquanto que apenas um atestou a favor da integridade dos padrões utilizados.

Como de praxe, a unidade de concentração mais empregada nos resultados foi $\mathrm{mg} \mathrm{L}^{-1}$. Para fins de comparação com os valores de referência (Portaria 518), esta unidade foi, de fato, a escolha mais adequada, pois os valores legislados também são reportados em $\mathrm{mg} \mathrm{L}^{-1}$. Apenas alguns poucos resultados foram reportados em $\mu \mathrm{g} \mathrm{L}^{-1}$. Entretanto, reportar resultados seguidos de unidades diferentes em um único documento pode comprometer até mesmo a fidedignidade do resultado fornecido no laudo de análise. Neste caso, equívocos simples, tais como erros de digitação e formatação de planilhas eletrônicas, podem alterar o resultado reportado. Um dos laboratórios, por exemplo, uniformizou sua planilha de resultados para fornecer, automaticamente, quatro dígitos após a vírgula. Ao empregar diferentes unidades no relatório, apresentou resultados como $0,0100 \mathrm{mg} \mathrm{L}^{-1}$ de $\mathrm{Pb}, 21,8200 \mathrm{mg} \mathrm{L}^{-1}$ de $\mathrm{Na}$ e incríveis $0,5000 \mu \mathrm{g} \mathrm{L}^{-1}$ de $\mathrm{Cd}$, ou seja, 0,0005000 $\mathrm{mg} \mathrm{L}^{-1}$. Mesmo em situações em que o laboratório possua um sistema de gestão da qualidade do resultado, com ênfase no incremento da precisão do método, torna-se evidente a necessidade de se ponderar o número de algarismos significativos levando-se em consideração que apenas o último dígito deve ser objeto de dúvida. 
Dentre os 19 laboratórios avaliados neste trabalho, somente 3 manifestaram, no documento de apresentação dos resultados, o fato de possuírem algum tipo de credenciamento. Porém, ao consultar o sítio eletrônico dos laboratórios, verificou-se que 5 deles eram acreditados segundo os critérios da NBR 17.025. Quatorze laboratórios indicaram o nome do responsável pela empresa e/ou do analista. Entretanto, apenas 10 disponibilizaram seus endereços e formas de contato no documento. Quanto às condições estabelecidas no momento da contratação dos laboratórios, ou seja, analisar a amostra fornecida à luz dos padrões de potabilidade da água segundo a Portaria MS-518, 11 anexaram, em seus documentos, os valores máximos toleráveis para os elementos investigados e somente 8 emitiram pareceres técnicos com base na comparação entre os resultados reportados e os valores legislados. É importante mencionar que os contratantes valorizam conselhos e orientações sobre assuntos técnicos, bem como opiniões e interpretações baseadas nos resultados. ${ }^{4}$

\section{CONSIDERAÇÕES FINAIS}

Os resultados mostrados neste exercício analítico evidenciaram que a fidedignidade dos resultados por laboratórios prestadores de serviço é baixa. Apenas $35 \%$ dos dados gerados por um conjunto de 19 laboratórios foram considerados válidos. Além disso, devese destacar que $25 \%$ dos resultados válidos foram expressos com base no limite de detecção ou quantificação do método analítico empregado por cada laboratório. Os resultados globais mostraram ainda que o desempenho de mais da metade dos laboratórios foi inadequado, sendo que alguns laboratórios forneceram resultados tão distantes do esperado, fato este que demanda uma ação corretiva imediata. De modo geral, não mais que 3 laboratórios apresentaram um desempenho aceitável.

A avaliação da exatidão de um resultado fornecido por um prestador de serviço, assim como a rastreabilidade do mesmo, não deve ser apenas direito, mas também dever do contratante. No Brasil, a adequação em programas de gestão da qualidade, por parte de laboratórios prestadores de serviço, ainda é um tema recente. O INMETRO, por exemplo, vem difundindo a importância da acreditação de laboratórios de ensaios químicos por meio da NBR ISO/IEC 17025. Entretanto, o número de laboratórios detentores deste critério da qualidade ainda é insignificante frente ao número total de laboratórios de análises químicas situados no Brasil. Mesmo assim, considerando-se os resultados mostrados, verifica-se que a acreditação de um laboratório não garante que o mesmo forneça resultados fidedignos. Há falhas na implementação da confiabilidade em processos metrológicos em laboratórios, mesmo daqueles que são acreditados. O inverso também pode ser verificado, uma vez que laboratórios de ensaios químicos também podem possuir um programa efetivo de QA/QC sem estarem devidamente credenciados por algum órgão.
De qualquer forma, a avaliação do desempenho de um prestador de serviço é uma prerrogativa de qualquer contratante, tendo-se em vista não apenas o aspecto comercial inerente a este tipo de transação, mas, principalmente, os desdobramentos legais e financeiros que os resultados apresentados podem desencadear. A fidedignidade de um resultado analítico é de importância ímpar dentro deste contexto, pois o mesmo pode implicar em tomada de decisões que poderão demandar recursos financeiros elevados, priorização de ações não previstas, alocação de recursos humanos, dentre outros.

Finalmente, considerando-se o cenário atual envolvendo cada vez mais a sociedade civil e o Estado em questões ambientais e de saúde do planeta, resultados analíticos fidedignos são de extrema importância para a avaliação de passivos e ativos ambientais, norteadores de decisões de controle e intervenção.

\section{MATERIAL SUPLEMENTAR}

No material suplementar, disponível gratuitamente em http:// quimicanova.sbq.org.br na forma de arquivo PDF, é mostrado o desempenho global dos 19 laboratórios (Figuras 1Sa, 1Sb e 1Sc), assim como a distribuição dos resultados obtidos pelos laboratórios para cada um dos elementos químicos investigados dentro da faixa estatisticamente aceitável (Figuras 2Sa a 2Sg).

\section{REFERÊNCIAS}

1. Silva, V. M. P. A.; Carvalho, T. E. M.; Metrol. Instrum. 2006, 41, 20.

2. Miller, J. C.; Miller, J. N.; Statistics for analytical chemistry, $3^{\text {rd }}$ ed., Prentice Hall: New York, 1993.

3. Konieczka, P.; Critical Rev. Anal. Chem. 2007, 37, 173.

4. INMETRO; NBR ISO/IEC 17025:2005: Requisitos gerais para competência de laboratórios de ensaios e calibração, Associação Brasileira de Normas Técnicas: São Paulo, 2005.

5. IBAMA; Portaria Conjunta $N^{o} 66$ de 17 de junho de 1997, Instituto Brasileiro do Meio Ambiente e dos Recursos Naturais Renováveis: Brasília, 1997.

6. INMETRO; Portaria $N^{o} 029$ de 02 de maio de 1995: Vocabulário Internacional de Termos Fundamentais e Gerais de Metrologia, Instituto Nacional de Metrologia, Normalização e Qualidade Industrial: Rio de Janeiro, 2007.

7. MS; Portaria $N^{o} 518$ de 25 de março de 2004, Ministério da Saúde: Brasília, 2004.

8. APHA, AWWA, WEF; Standard Methods for the Examination of Water and Wastewater, $19^{\text {th }}$ ed., American Public Health Association: Washington, 1995.

9. Chui, Q. S. H.; Bispo, J. M. A.; Iamashita, C. O.; Quim. Nova 2004, 27, 993.

10. Horwitz, W.; Pure Appl. Chem. 1988, 60, 855. 


\section{DESEMPENHO ANALÍTICO DE LABORATÓRIOS PRESTADORES DE SERVIÇO NA DETERMINAÇÃO DE METAIS EM ÁGUAS}

Wilson F. Jardim* e Fernando F. Sodré

Departamento de Química Analítica, Instituto de Química, Universidade Estadual de Campinas, CP 6154, 13084-862 Campinas - SP, Brasil
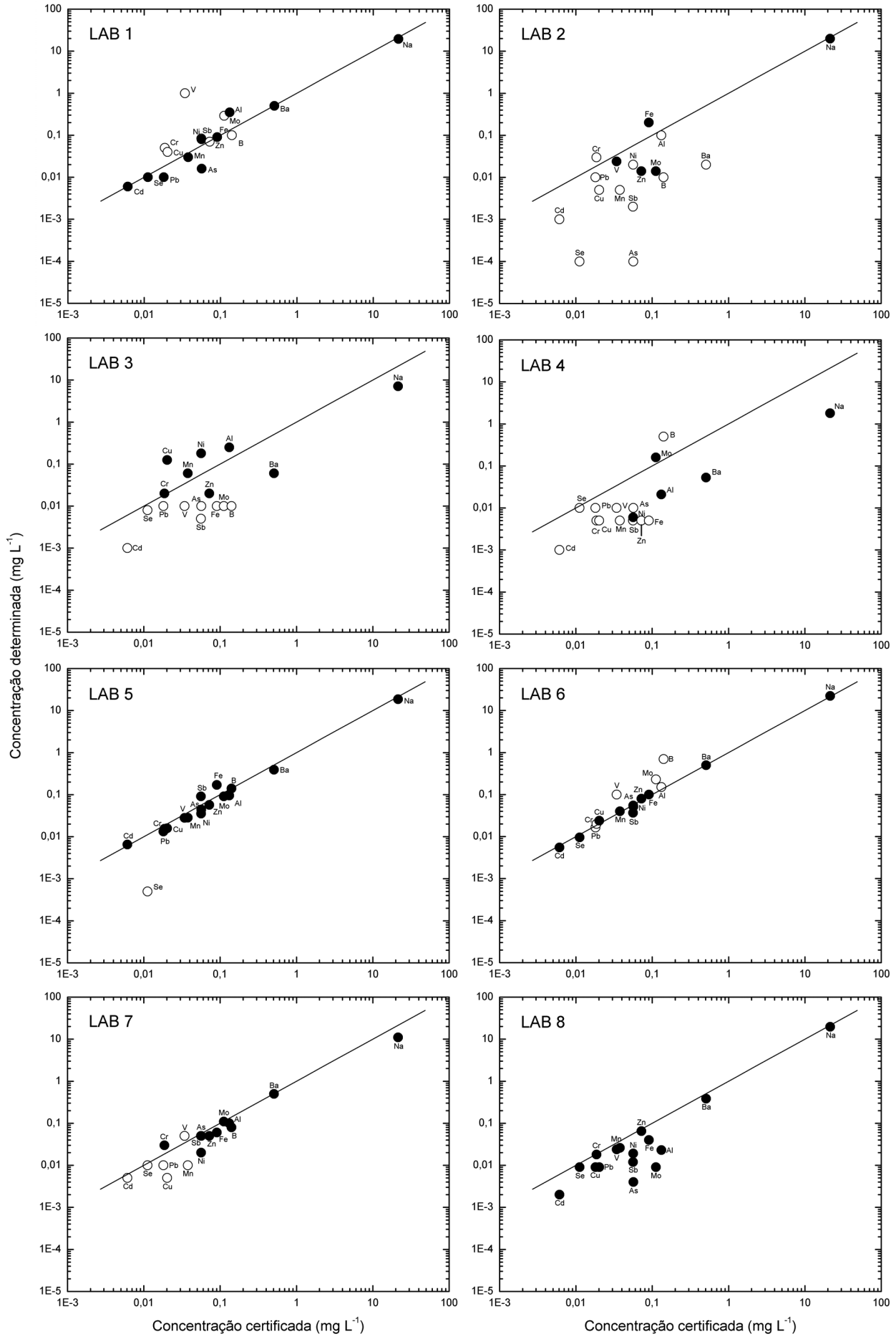

Figura 1Sa. Distribuição dos resultados obtidos pelos laboratórios 1, 2, 3, 4, 5, 6, 7 e 8 em função dos valores certificados. A reta indica valores obtidos e certificados idênticos. Círculos cheios são resultados experimentais e círculos não preenchidos são valores de limite de detecção ou de quantificação 

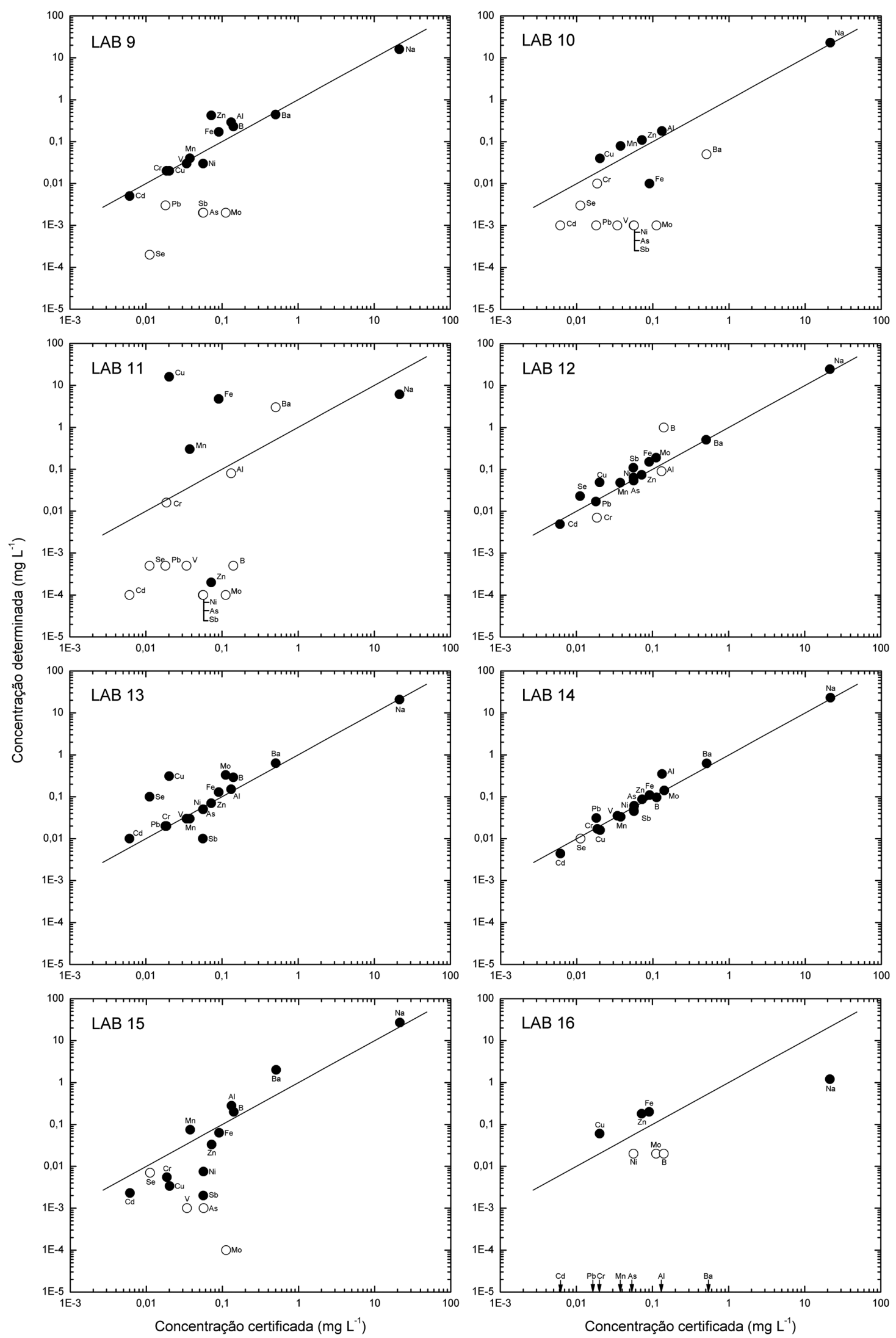

Figura 1Sb. Distribuição dos resultados obtidos pelos laboratórios 9, 10, 11, 12, 13, 14, 15 e 16 em função dos valores certificados. A reta indica valores obtidos e certificados idênticos. Círculos cheios são resultados experimentais e círculos não preenchidos são valores de limite de detecção ou de quantificação 

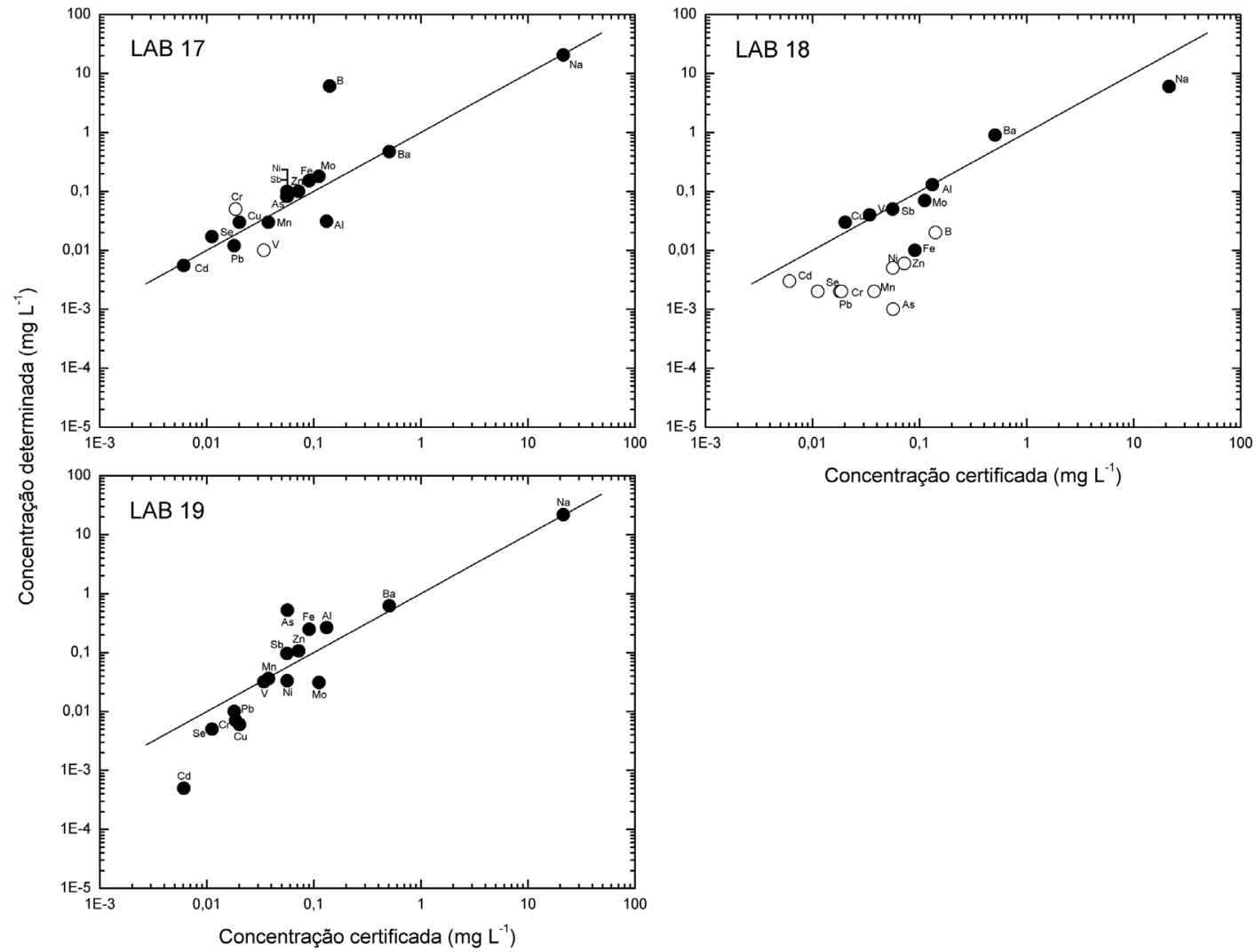

Figura 1Sc. Distribuição dos resultados obtidos pelos laboratórios 17, 18 e 19 em função dos valores certificados. A reta indica valores obtidos e certificados idênticos. Círculos cheios são resultados experimentais e círculos não preenchidos são valores de limite de detecção ou de quantificação

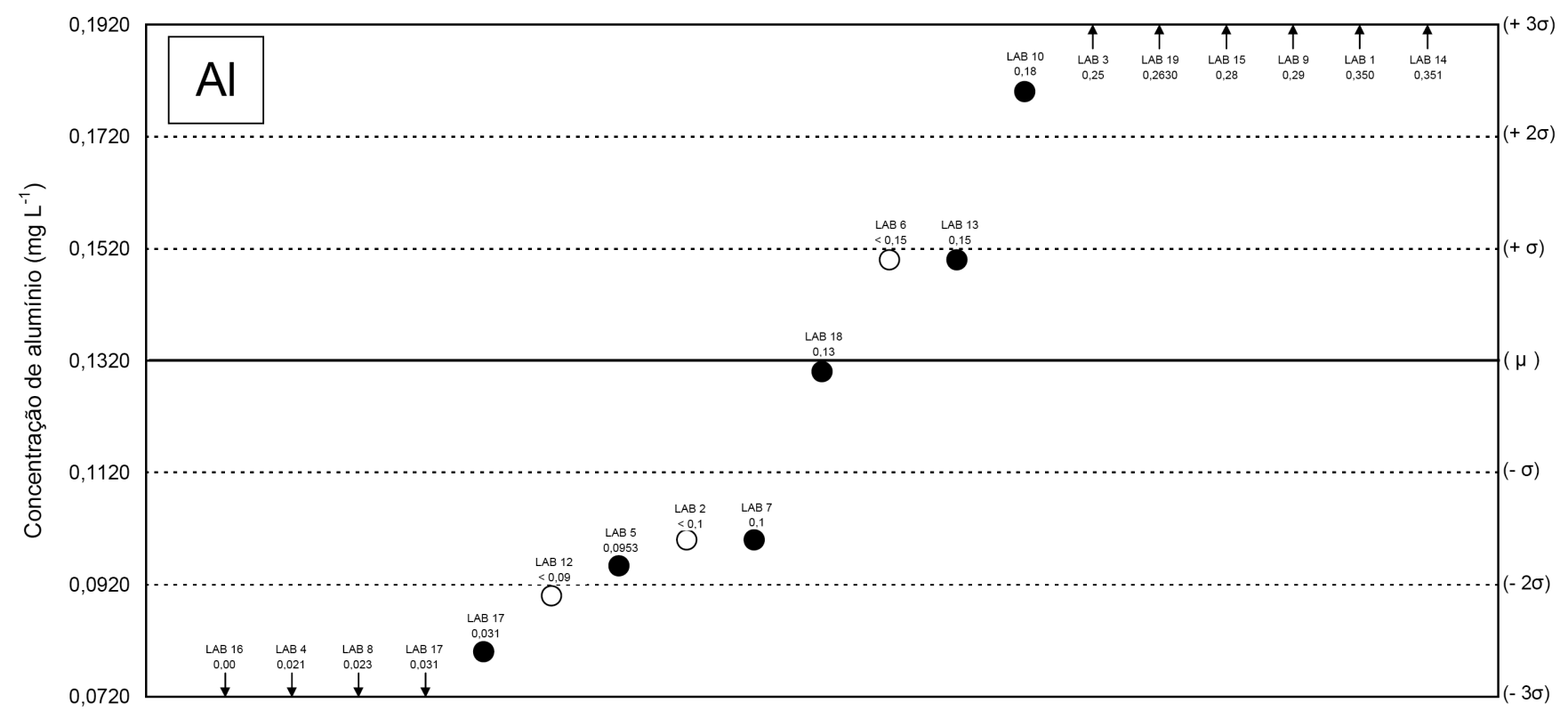

Figura 2Sa. Variabilidade das concentrações de alumínio, em ordem crescente, dentro da faixa de aceitação ( $\mu \pm 3 \sigma)$. Círculos cheios são resultados experimentais e círculos não preenchidos são valores de limite de detecção ou de quantificação 

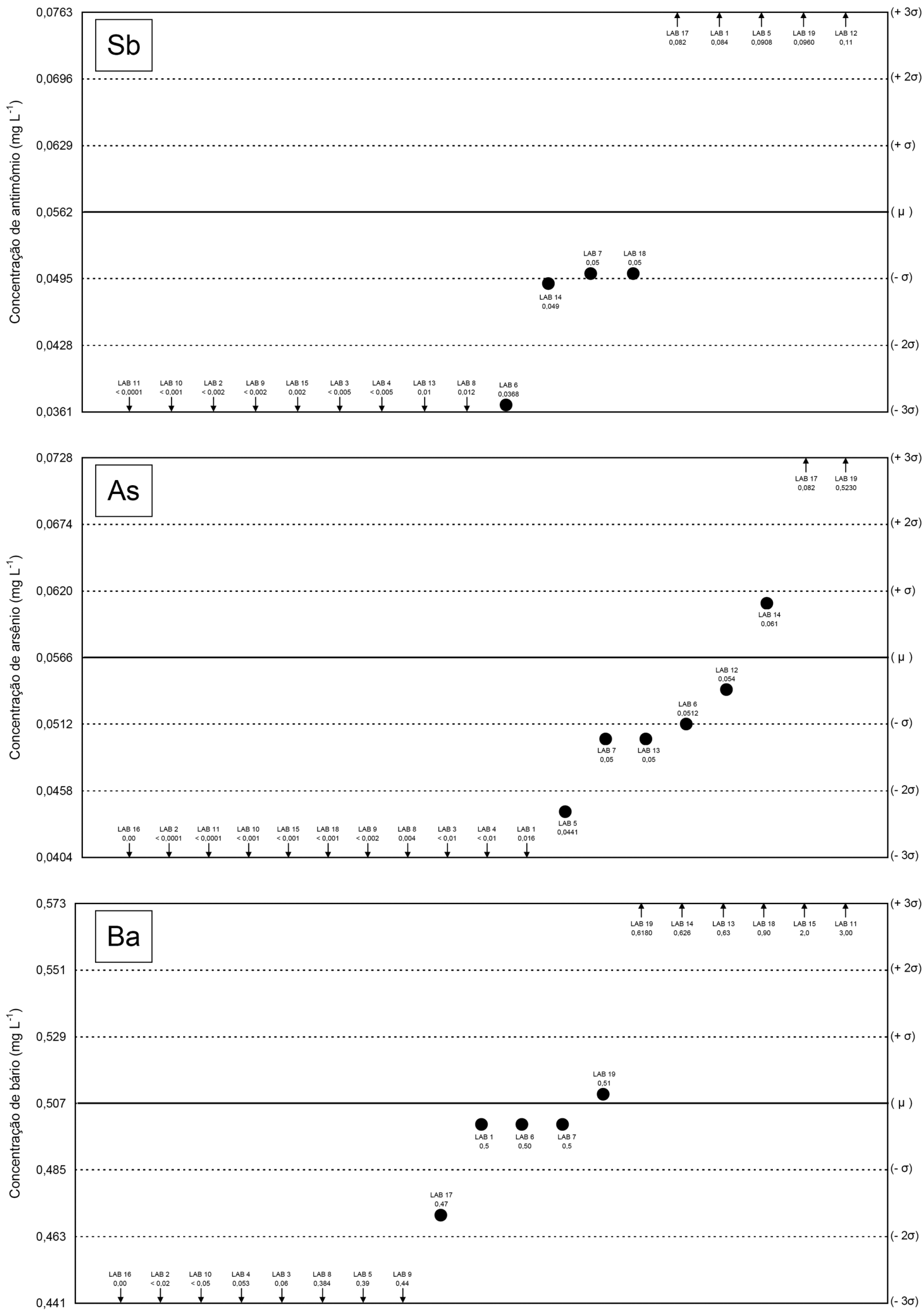

Figura 2Sb. Variabilidade das concentrações de antimônio, arsênio e bário, em ordem crescente, dentro da faixa de aceitação $(\mu \pm 3 \sigma)$. Círculos cheios são resultados experimentais e círculos não preenchidos são valores de limite de detecção ou de quantificação 

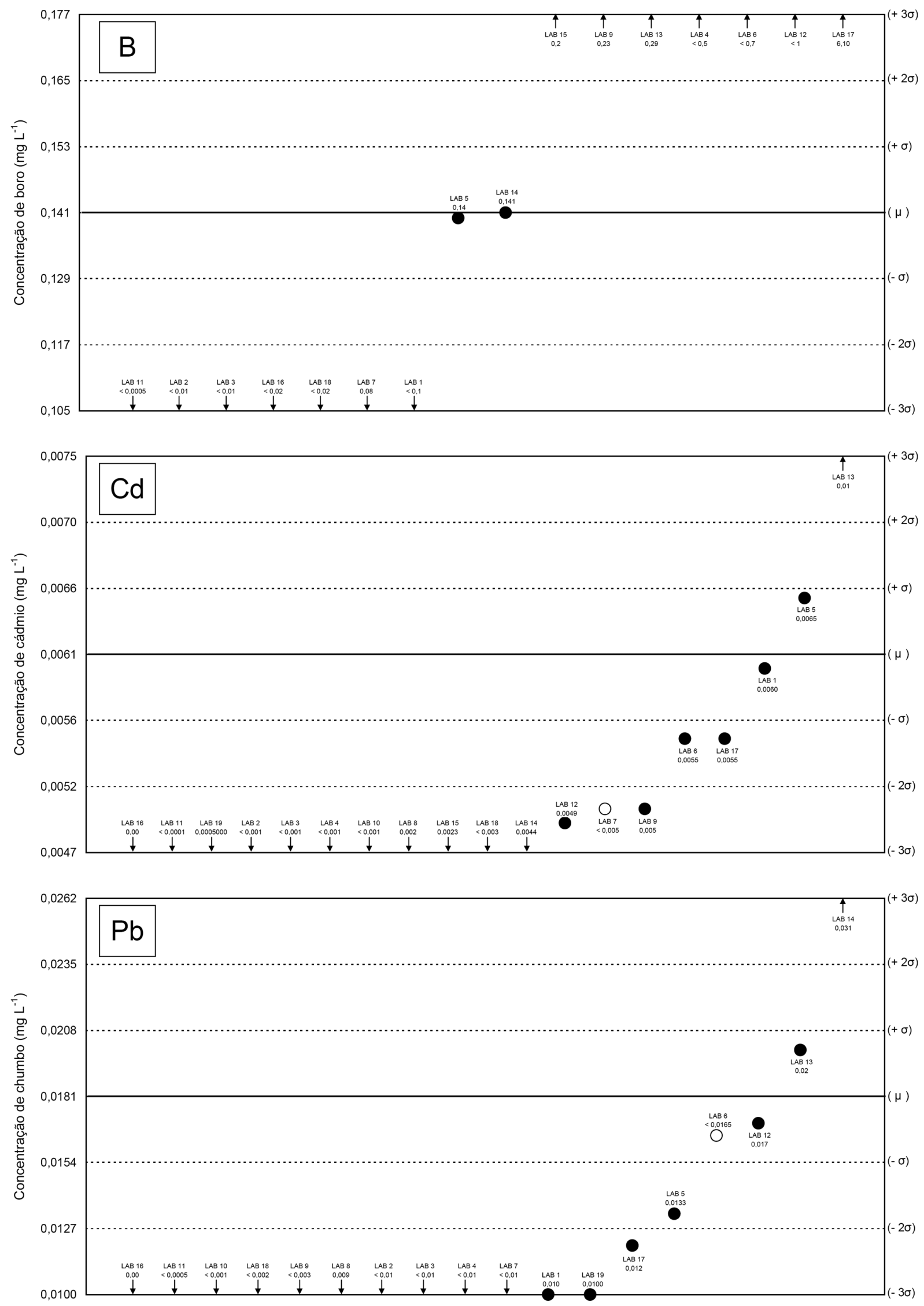

Figura 2Sc. Variabilidade das concentrações de boro, cádmio e chumbo, em ordem crescente, dentro da faixa de aceitação ( $\mu \pm 3 \sigma)$. Círculos cheios são resultados experimentais e círculos não preenchidos são valores de limite de detecção ou de quantificação 

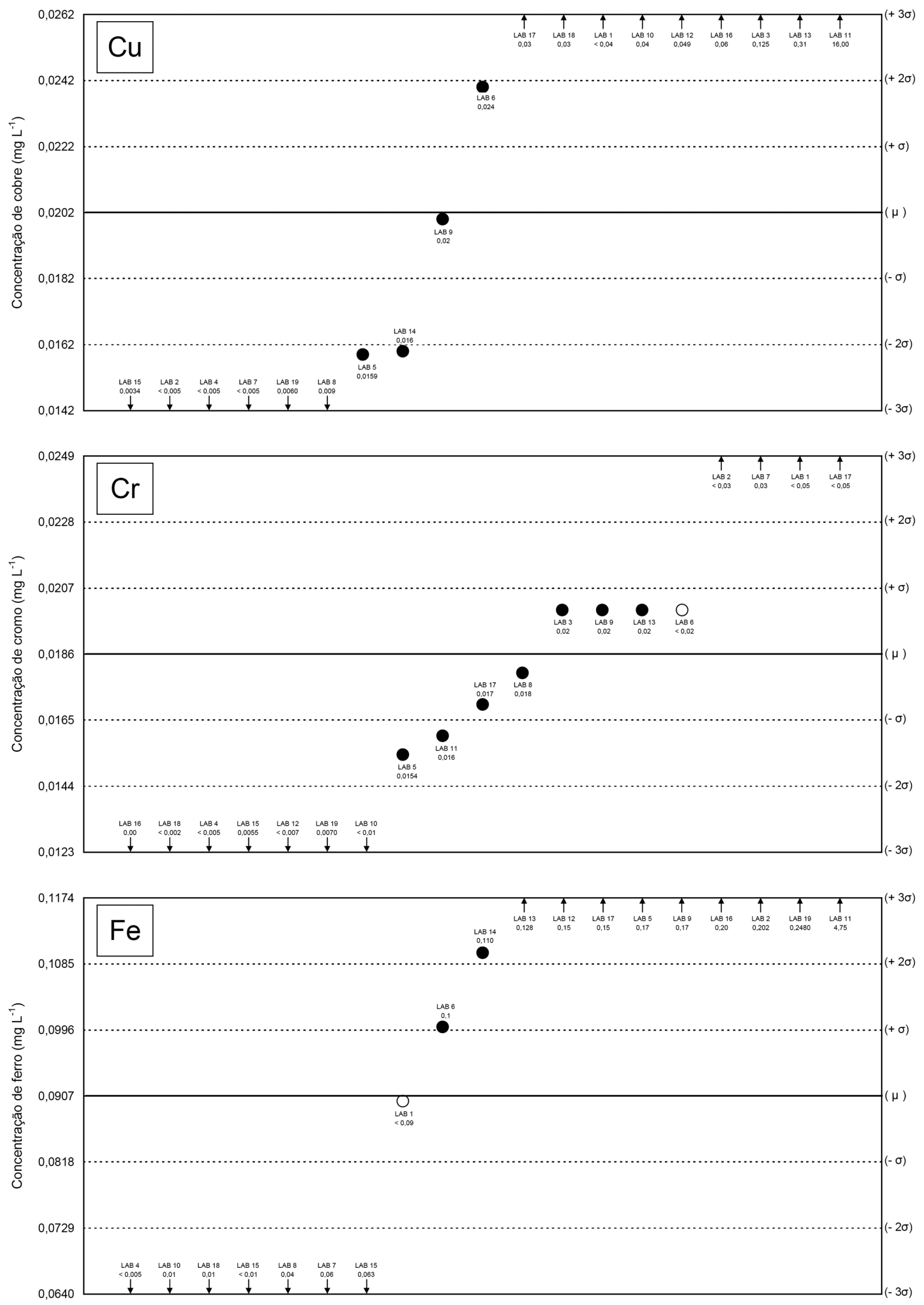

Figura 2 Sd. Variabilidade das concentrações de cobre, cromo e ferro, em ordem crescente, dentro da faixa de aceitação ( $\mu \pm 3 \sigma)$. Círculos cheios são resultados experimentais e círculos não preenchidos são valores de limite de detecção ou de quantificação 

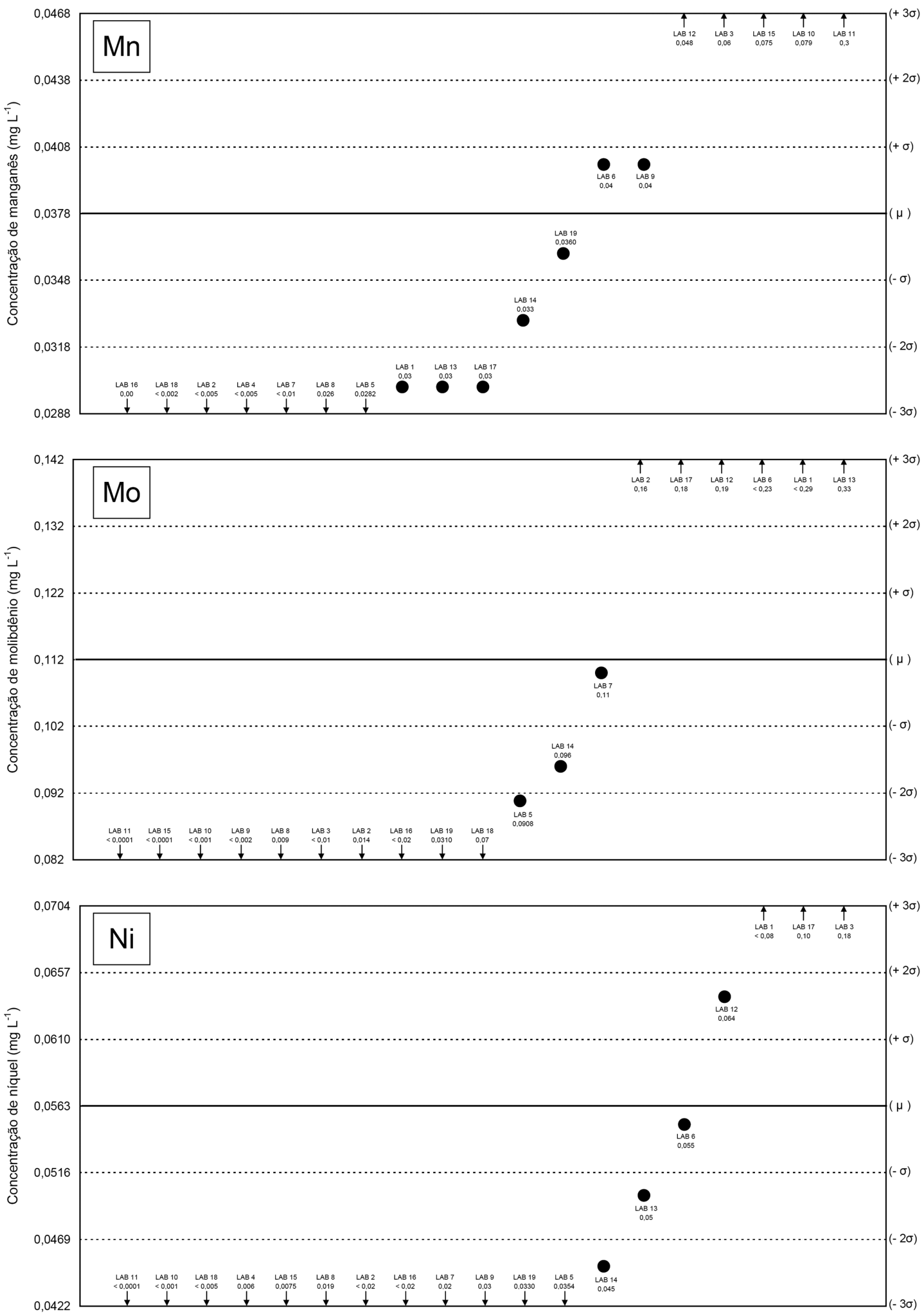

Figura 2 Se. Variabilidade das concentrações de manganês, molibdênio e níquel, em ordem crescente, dentro da faixa de aceitação ( $\mu \pm 3 \sigma)$. Círculos cheios são resultados experimentais e círculos não preenchidos são valores de limite de detecção ou de quantificação 

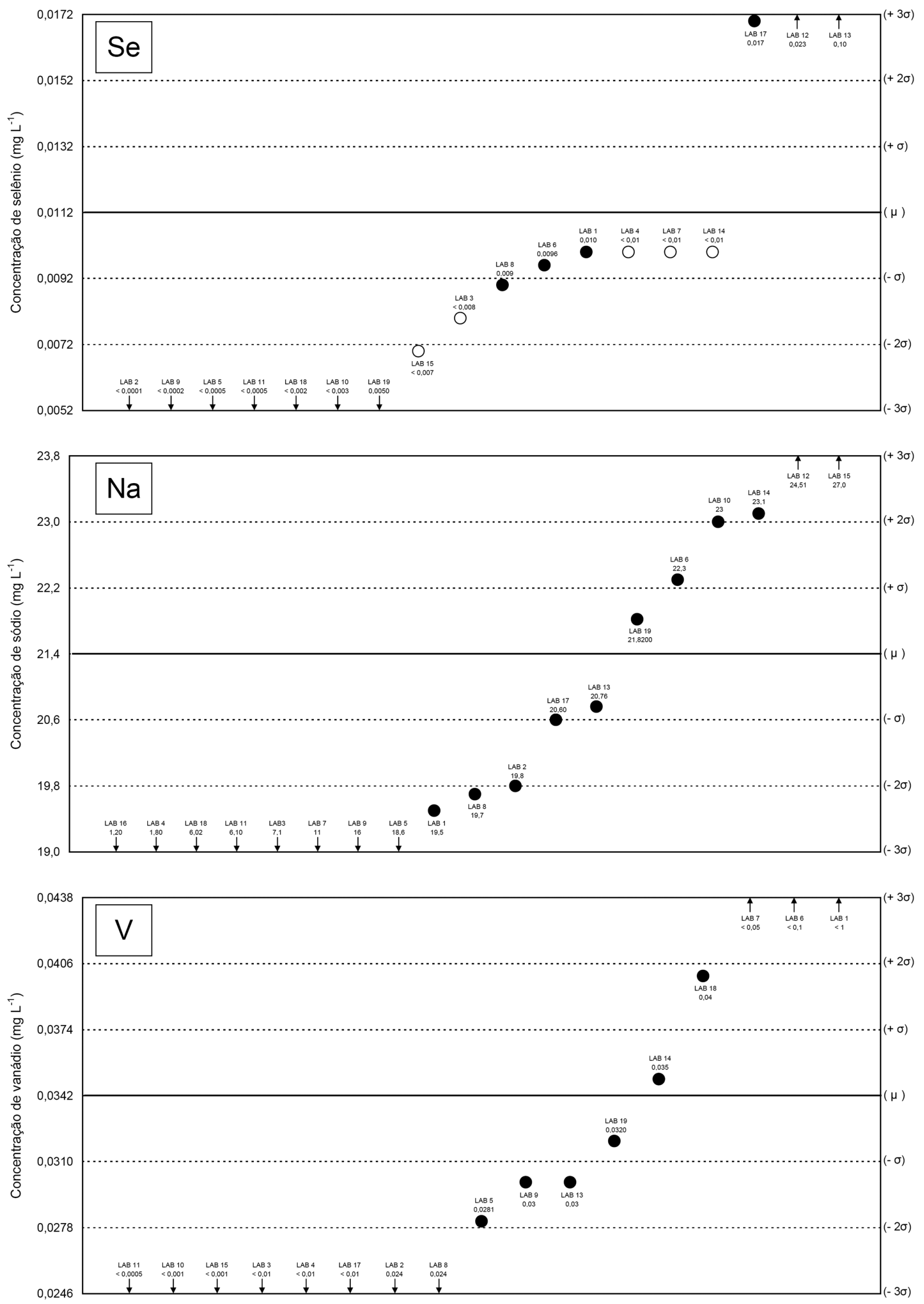

Figura 2Sf. Variabilidade das concentrações de selênio, sódio e vanádio, em ordem crescente, dentro da faixa de aceitação ( $\mu \pm 3 \sigma)$. Círculos cheios são resultados experimentais e círculos não preenchidos são valores de limite de detecção ou de quantificação 


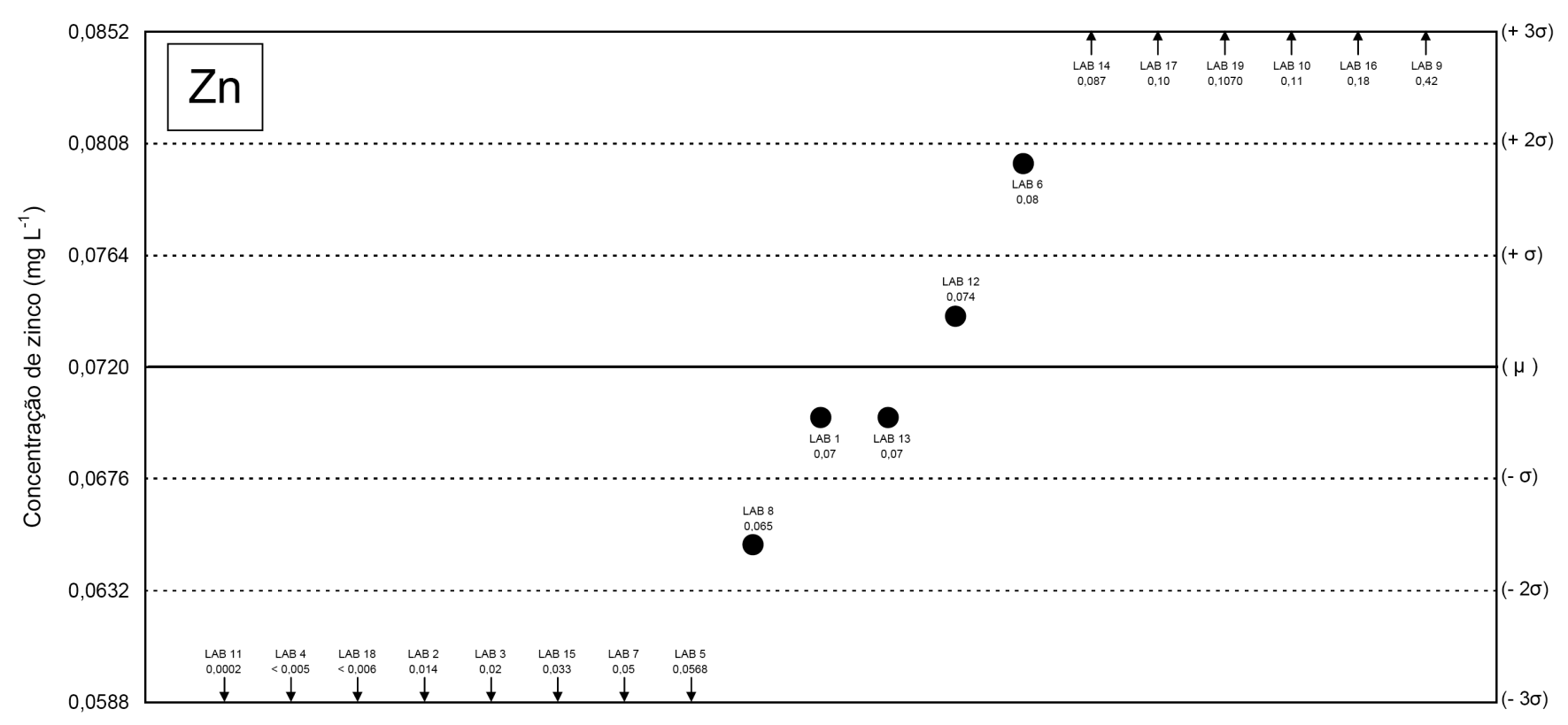

Figura 2 Sg. Variabilidade das concentrações de zinco, em ordem crescente, dentro da faixa de aceitação $(\mu \pm 3 \sigma)$. Círculos cheios são resultados experimentais e círculos não preenchidos são valores de limite de detecção ou de quantificação 